\title{
Procesos de cambio en la sociedad rural española. Pluralidad de intereses en una nueva estructura de oportunidades
}

\author{
Eduardo M oyano
}

IESA-CSIC de Andalucía

Campo Santo de los M ártires, 7. 14004 Córdoba (Spain)

emoyano@iesaa.csic.es

\section{Resumen}

El objetivo de este artículo es analizar cómo se percibe el actual contexto de cambios en la sociedad rural española y cómo responden al mismo los distintos grupos sociales. Para ello, partimos de una tesis inicial según la cual el actual proceso de cambio no es percibido de forma homogénea, sino diferenciada por los grupos que componen la sociedad rural. Así, mientras que unos grupos - la mayor parte de los agricultores y asalariados agrícolas- lo perciben en términos de crisis, de final de una época, de pérdida de derechos adquiridos, otros - sobre todo, grupos de intereses no agrarios, pero también grupos innovadores de agricultores- lo perciben como una oportunidad para aprovechar de modo diferente los recursos endógenos, es decir, como el comienzo de una etapa nueva en la que el espacio rural comience a ser gestionado en consonancia con la pluralidad de intereses que en él confluyen. D e acuerdo con esta tesis de partida, se analizará, en primer lugar, el actual proceso de cambio, prestando atención a aquellos elementos (económicos, sociales, culturales y políticos) que afectan más directamente al estatus de la agricultura y el mundo rural y que explican las nuevas demandas de la sociedad y la emergencia de una nueva estructura de oportunidades. En segundo lugar, se anal iza cómo es percibida dicha estructura de oportunidades por tales actores (agricultores y no agricultores) y cuál es su capacidad de acceso a los recursos disponibles, analizándose finalmente las respuestas que dan a los problemas que les afectan.

Palabras clave: cambio social, desarrollo rural, España, política agraria.

Abstract. Process of change in the Spanish rural society. Plurality of interests in a new opportunity structure

The aim of this article is to analyse the way in which the present process of change is perceived within the Spanish rural society. To do this we shall take as our starting point the thesis that the perception of change is not homogeneous, but is differentiated according to the different groups that comprise rural society. Some, including most farmers and agricultural workers, see it as a traumatic crisis, the end of an era and the loss of their rights, while others, those not involved in agriculture and more forward looking farmers, see it as an opportunity to exploit endogenous resources in different ways, and as the 
beginning of a new era, in which the countryside can be managed in harmony with the plurality of interests coexisting within it. To begin with, we shall analyse the present process of change, paying particular attention to those factors (economic, social, political and cultural) that affect agriculture and rural society most directly, and which explain the new expectations and the emergence of a new opportunity structure. In the second section we shall look at how this opportunity structure is perceived by those concerned, both farmers and non farmers, and analyse their responses to the problems they face.

Key words: agricultural policy, rural development, social change, Spain.

\section{Sumario}
Introducción
Conclusiones
El contexto de cambios
Bibliografía

Distintas percepciones del cambio

en la sociedad rural española

\section{Introducción}

Puede parecer una obviedad decir que nos encontramos ante un proceso de cambio en los ámbitos social, económico y cultural, pero es un hecho del que hay que partir para comprender muchas de las cosas que acontecen en esta coyuntura de fin de milenio. En ese contexto de cambios, se revisan muchos de los principios que han inspirado las políticas públicas en el periodo posterior a la Segunda Guerra M undial, cuestionándose incluso la viabilidad del propio Estado del bienestar tal como ha sido construido en ese periodo. Al margen de las disputas ideológicas sobre la mayor o menor presencia del Estado, parece existir un consenso general sobre la necesidad de reformar las políticas públicas para reducir sus costes y aumentar su eficacia ante la ciudadanía. Q ue tal reforma se integre dentro de una doctrina que preconice la desregulación y retirada del Estado y el retorno de la sociedad civil, o bien de otra que siga apostando por el papel regulador del Estado para garantizar la equidad y el interés general, es asunto del debate político, debate en el que la reforma de las políticas públicas se plantea como un hecho necesario desde ambas posiciones.

La política agraria fue una de las primeras políticas asumidas en los años cincuenta por el Estado del bienestar para garantizar la seguridad alimentaria, y la primera incorporada como política común (PAC) al proceso de construcción europea en la cumbre celebrada en la ciudad italiana de Stressa ${ }^{1}$

1. Con motivo del cuarenta aniversario de la cumbre de Stresa, se publicó en distintos medios de comunicación europeos un manifiesto del Grupo de Brugge (Brujas) sobre la política agraria. La versión española se publicó con el título U na nueva política agraria para una nueva Europa (1997). 
(1958). Por ello, no debe extrañar que, una vez logrados los objetivos planteados en la PAC y tras los cambios experimentados por la agricultura en las dos últimas décadas, se haya producido en la Unión Europea (UE) un desfase entre, de un lado, los instrumentos utilizados por los poderes públicos para regular este sector $y$, de otro, los problemas que le afectan como consecuencia de las nuevas demandas de la sociedad. D e ahí que, desde 1992, se esté abordando en el seno de la U E la reforma de los mecanismos de regulación, es decir, de la política agraria tal como se ha venido aplicando en las tres últimas décadas. Políticas de desarrollo rural, de diversificación de actividades, de reforestación o agroambientales son al gunas de las nuevas políticas que surgen en el actual contexto de cambios y que pretenden responder a las nuevas demandas de la sociedad respecto a la utilización de los espacios rurales, así como al modelo de ordenación territorial a que se aspira en los albores del siglo XXI.

El objetivo de este artículo es analizar cómo se percibe este contexto de cambios en la sociedad rural europea y más particularmente en la española, y cómo responden al mismo los distintos grupos sociales. Para ello, partimos de una tesis inicial según la cual el actual proceso de cambio no es percibido de forma homogénea, sino diferenciada por los grupos que componen la sociedad rural. Así, mientras que unos grupos - la mayor parte de los agricultores- lo perciben en términos de crisis, de final de una época, de pérdida de derechos adquiridos, otros - sobre todo, grupos de intereses no agrarios, pero también grupos innovadores de agricultores- lo perciben como una oportunidad para aprovechar de modo diferente los recursos endógenos, es decir, como el comienzo de una etapa nueva en la que el espacio rural comience a ser gestionado en consonancia con la pluralidad de intere ses que en él confluyen.

D e acuerdo con esta tesis de partida, se analizará, en primer lugar, el actual proceso de cambio, prestando atención a aquellos elementos (económicos, sociales, culturales y políticos) que afectan más directamente al estatus de la agricultura y el mundo rural y que explican las nuevas demandas de la sociedad y la emergencia de nuevos grupos de intereses. D esde un punto de vista sociológico, y utilizando una metodología de corte boudoniano, este contexto de cambio estaría actuando como una nueva estructura de oportunidades ${ }^{2}$ para la acción tanto individual como colectiva de los distintos actores que componen la sociedad rural española, una estructura que no les impone de forma determinista ningún tipo de acción, sino que les ofrece recursos para ser aprovechados según la particular forma que tienen estos actores de percibir e interpretar el proceso de cambio en el que están inmersos y de acuerdo con su mayor o menor capacidad de acceder a ellos. D e ahí, que en un segundo apartado se analice cómo es percibida dicha estructura de

2. La noción de «estructura de oportunidades», utilizada en el enfoque de la movilización de recursos para el análisis de los movimientos sociales (C asquete, 1998), se corresponde con la de «sistema de acción» de Boudon. 
oportunidades por tales actores (agricultores y no agricultores) y cuál es su capacidad de acceso a los recursos disponibles, analizándose finalmente las respuestas que dan a los problemas que les afectan.

\section{El contexto de cambios}

En lo que se refiere a la agricultura y el mundo rural, el actual contexto de cambios puede caracterizarse por una serie de elementos interrelacionados cuyos efectos se dejan sentir en el terreno económico, social, político y cultural. Sólo con una finalidad analítica se procederá a analizarlos de forma separada.

\section{a) Cambios socioeconómicos}

D esde el punto de vista económico, es un hecho la pérdida de importancia de la agricultura como actividad productiva, hecho que se expresa en la paulatina reducción de la población activa agraria (un $5 \%$ como media en la U E en 1997, descendiendo a un ritmo anual del 2-3\% y reduciéndose el número de agricultores y el de asalariados agrícolas) y en el cada vez menor peso específico de la producción agrícola y ganadera en el PIB de los países que componen la UE (2\% como media, según datos de 1998). Aunque hay diferencias importantes a nivel regional dentro de la UE - especialmente entre las regiones del centro y norte europeos y las del sur, existiendo en estas últimas un importante sector de asalariados agrícolas como es el caso español- , puede afirmarse, no obstante, que, en términos generales, es un hecho el declive de la agricultura como sector productivo, sin que ello signifique ignorar su importancia para el equilibrio territorial o para el dinamismo de muchas zonas rurales al continuar dependiendo de ella muchas otras actividades colaterales de carácter industrial o de servicios (talleres de maquinaria agrícola, empresas de fertilizantes o pesticidas, empresas de seguros, etc.).

A parte de esta tendencia de carácter general, lo importante a los efectos del hilo argumental de este trabajo radica en el hecho de que estas otras actividades son desarrolladas por actores económicos imbuidos de una lógica empresarial no dependiente de las subvenciones públicas, lo que les hace valorar, de forma diferente a como ha sido tradicional entre los agricultores, la utilización y aprovechamiento de los espacios y territorios que componen el mundo rural. Para estos actores económicos, los agricultores no pasan de ser unos clientes más o menos interesantes para la buena marcha de sus respectivos negocios, unos clientes con los que establecen relaciones instrumentales de naturaleza mercantil, pero con los que no necesariamente comparten un sistema común de valores a la hora de decidir cuál debe ser el destino del espacio y el territorio en su correspondiente comunidad. Si a ello añadimos el fenómeno de la pluriactividad cada vez más frecuente entre determinados sectores de agricultores o el de la externalización de las labores agrícolas, nos encontramos además con una población agraria en la que 
nuevos valores - alejados de los que han guiado tradicional mente sus decisiones- están presentes a la hora de definir sus estrategias económicas.

Asimismo, los espectaculares avances en el campo de las telecomunicaciones y las mejoras en las infraestructuras viarias han reducido el tradicional aislamiento de las zonas rurales y propiciado la instalación de nuevas actividades industriales y de servicios aprovechando las condiciones favorables que les ofrecen los gobiernos local es en su afán de atraer inversiones que generen empleo y riqueza. En torno a estas actividades económicas no relacionadas directamente con la agricultura, emerge un nuevo y cada vez más importante segmento de empresarios y profesionales autónomos formado en la cultura del libre mercado, una cultura cuyo sistema de valores está también bastante alejado del de los agricultores.

Junto a las actividades ya comentadas, habría que mencionar aquellas otras ligadas directamente a la sociedad del bienestar y que están imprimiendo un dinamismo sin precedentes al mundo rural. Entre ellas destacan, por un lado, las que derivan de los servicios públicos del Estado (por ejemplo, las relacionadas con los servicios sanitarios y de educación, o con los de asistencia social) y, por otro, las que derivan de las nuevas demandas de amplios segmentos de la población en materia de ocio (turismo, segunda residencia, tercera edad, ocio y actividades recreativas), actividades todas ellas que ocupan cada vez más a la población residente en el medio rural y que propician formas nuevas de integración sociolaboral, distintas de las que han sido tradicionales en este medio.

En definitiva, la estructura - tanto económica, como social- de la sociedad rural se ha hecho más compleja, con una mayor diferenciación dentro y fuera del sector agrario y con una mayor diversificación de las actividades y profesiones, aspectos éstos que tienen importantes efectos en la vida local, al reducir el protagonismo de las élites agrarias tradicionales y propiciar el ascenso de nuevas élites. Ello abre una nueva dinámica a nivel local y crea una nueva estructura de oportunidades para la acción política, una acción que puede venir marcada por la cooperación o la confrontación entre nuevos y vie jos actores, según como estos actores perciban el actual proceso de cambio que experimenta la sociedad rural.

\section{b) Cambios culturales}

En el campo de la cultura pueden distinguirse dos importantes cambios. Por un lado, el avance de los llamados valores posmaterial istas (Inglehart, 1977), que ha dado lugar a que sectores cada vez más amplios de la población se preocupen por aspectos no relacionados directamente con la satisfacción de necesidades materiales - entre ellos, el problema de satisfacer la necesidad básica de la alimentación, un problema que consideran resuelto con el actual nivel de desarrollo científico y tecnológico y con la posibilidad de recurrir a mercados fácilmente asequibles- , sino por aspectos situados en el ámbito de la calidad de vida - como por ejemplo el deterioro de los recursos natura- 
les, la pérdida de la biodiversidad, la degradación del paisaje, la contaminación de los ríos 0 , más recientemente, la seguridad y calidad de los alimentos. Se produce, así, un importante cambio cultural en sectores cualificados de la opinión pública, que plantean con cada vez mayor frecuencia la sustitución del modelo de desarrollo productivista a ultranza - que, como es conocido, fue dominante en los países occidental es hasta los años ochentapor otro de desarrollo sostenible que tenga sus principios básicos en la calidad y en una más equilibrada utilización de los recursos naturales. Todo ello compone un marco nuevo de referencia - en torno al concepto de sustentabilidad acuñado con ocasión del ya célebre Informe Brundtland- a la hora de definir la utilización del espacio rural, un marco que da legitimidad a las demandas de los nuevos grupos sociales, pero que, al mismo tiempo, introduce importantes restricciones a su utilización como espacio de producción agrícola (M oyano y Paniagua, 1998).

Por otro lado, y dentro del ámbito cultural, destaca un segundo elemento de cambio, cual es el fenómeno de recuperación de «o local» que se ha producido en estas dos últimas décadas de forma paralela a como se ha venido extendiendo el fenómeno de la mundialización ${ }^{3}$. Ambos son fenómenos de lógicas aparentemente contradictorias, pero que, vistos con más detenimiento, guardan una profunda coherencia, ya que la recuperación de «lo local» se corresponde con un proceso identitario, de búsqueda de raíces y de referencias tangibles, de cercanía y proximidad, en un mundo multicultural cada vez más globalizado cuyas coordenadas, tanto físicas como sociales, se extienden y diluyen a escala planetaria (D onati, 1997). En ese contexto, la gente redescubre «o local», realza los valores de sus pueblos y apuesta por permanecer en ellos procurando dotarlos de equipamientos y aprovechando las ventajas comparativas que les ofrecen ahora los avances técnicos y telemáticos propiciados precisamente por ese mismo proceso de globalización. Los proyectos de desarrollo local intentan abrirse paso a través de lo que algunos autores denominan con acierto los intersticios de la globalización (Renard, 1996 y 1998), unos proyectos en los que se pretende valorizar los recursos endógenos (materiales y socioculturales) para hacer viables formas diferenciadas de desarrollo que permitan la permanencia de la población en sus comunidades rurales y, con ello, el dinamismo de sus pueblos. Este fenómeno tiene importantes repercusiones en el ámbito económico y político, habiéndose situado en el centro de las políticas públicas y dando pie a que se hable incluso de un nuevo localismo como elemento revitalizador de la democracia en el ámbito local (N avarro Yáñez, 1997; Giménez Guerrero, 1998).

En definitiva, puede afirmarse la existencia de un nuevo contexto cultural en la sociedad rural, marcado, de una parte, por una nueva valoración del espacio y el territorio en la que se introducen criterios relacionados más con la calidad de vida que con la producción y, de otra, por una revitalización de

3. Para un análisis de la dialéctica entre lo global y lo local en el mundo rural, puede verse Entrena (1998). 
lo local como marco central de referencia para el conjunto de la población. Al igual que con los factores económicos antes comentados, este contexto también crea una nueva estructura de oportunidades (culturales y simbólicas) que puede ser aprovechada por los distintos actores económicos y social es según su particular interpretación del actual proceso de cambio.

\section{c) Cambios políticos}

Algunos hechos acontecidos en la última década marcan de modo innegable el contexto de referencia en que se plantean los problemas de la sociedad rural europea, en general, y española, en particular. D estacan, en primer lugar, los acuerdos del GAT T sobre liberalización del comercio agrícola - firmados en la ciudad marroquí de $M$ arraquech en abril de 1994 y luego continuados en la O M C (O rganización M undial del Comercio), cuya primera reunión ha tenido lugar en Seattle el pasado mes de noviembre- , acuerdos cuyas implicaciones políticas son indudables al limitar los márgenes de maniobra de los gobiernos nacionales para mantener en vigor sus tradicionales políticas proteccionistas, particularmente las dirigidas al sector agrario (D elorme y Le Theule, 1996). Algunas de esas implicaciones se vieron ya en la reforma de las O CM de cereales y oleaginosas emprendida en 1992 dentro de la UE, y están marcando ahora la tendencia hacia una reducción progresiva de los precios agrícolas y su equiparación a los precios de mercado, así como hacia la eliminación de todo tipo de subvenciones a la producción - para hacer que disminuyan los precios internos y se reduzcan los excedentes agrícolas, evitando sus efectos negativos sobre los mercados internacionales- y su sustitución por sistemas de ayudas directas a la renta, tal como se ha planteado en la Agenda $2000^{4}$.

Este hecho, de natural eza política, tiene importantes repercusiones económicas y culturales para el sector agrario al introducir en el contexto de referencia de los agricultores un nuevo factor, a saber: la competitividad, hasta ahora relegada sólo a aquellos sectores no amparados por el paraguas de las políticas proteccionistas. Repercusiones económicas, porque en este nuevo contexto los distintos actores (agricultores, cooperativas y empresas agroalimentarias en general) se ven impelidos a tener en cuenta el tema de la competitividad, tanto para evitar los riesgos de una mayor competencia como para aprovechar las oportunidades de mercados más amplios que ese nuevo contexto les ofrece. Repercusiones culturales, porque este nuevo contexto exige una nueva definición de las estrategias individuales y colectivas y hace nece-

4. La «Agenda 2000» es un documento elaborado por la Comisión Europea y dirigido al Consejo, en el que se marcan las líneas directrices de las distintas políticas europeas - entre ellas la agraria - para el periodo 2000-2006 y las previsiones presupuestarias para su financiación. El escenario de ese documento es el de la ampliación de la UE a Chipre y a cuatro países del Este (PECO s): Eslovenia, Polonia, H ungría y República Checa. El documento fue aprobado por el Consejo Europeo en la cumbre de Berlín en junio de 1999. 
sarios cambios importantes en la formación del capital humano y en la mentalidad empresarial de los agricultores.

En segundo lugar, la marcha del proceso de construcción europea repre senta otro factor político de indudable importancia por dos principales razones. D e un lado, por el hecho de la ampliación de la U E a los países del Este - llamados PEC O s en la terminología comunitaria - , unos países caracterizados, como se sabe, por una el evada proporción de población agrícola, por una escasa modernización de sus estructuras agrarias, por un importante déficit en infraestructuras viarias y de comunicación y por un deficiente nivel de formación de su capital humano. Esta situación, que, como ha quedado también reflejado en la Agenda 2000, supondrá un elevado coste para el presupuesto de la UE, obliga a introducir cambios importantes en la política agraria europea - concretamente, en la definición de los fondos estructurales- , ya que, de acuerdo con los informes procedentes de la Comisión Europea, la aplicación de la actual PAC sería inviable en una UE ampliada, sobre todo si se quiere que dicha ampliación se haga sin incrementar las aportaciones de los Estados miembros al presupuesto comunitario según el principio de neutralidad presupuestaria que se propone.

D e otro lado, el proceso de construcción europea supone también la incorporación de nuevas políticas al acervo comunitario (de medio ambiente, de educación, investigación y desarrollo, así como de infraestructuras en el marco de los fondos de cohesión), políticas para cuya financiación tendrán que detraerse recursos del presupuesto de la U E en detrimento de los que hasta ahora se venían destinando a la PAC. La que algunos autores han calificado «agricultural policy community» (Smith, 1990; Frouws y Van Tatenhoven, 1993; D augbjerg, 1997a y 1997b) - una especie de comunidad de intereses compartidos, formada por los encargados de aplicar la PAC y por sus principales beneficiarios (los agricultores y sus organizaciones) - pierde su cohesión interna $a^{5}$ se ve ahora en el brete de tener que competir por los recursos disponibles con otros grupos de intereses emergentes, en un contexto en el que la importancia de la agricultura ha cambiado en las agendas políticas y sociales europeas una vez alcanzada la suficiencia alimentaria en productos básicos e impuesto el principio de apertura y liberalización de los mercados agrícolas.

En tercer lugar, la posición estratégica y geopolítica de la UE en el contexto de las relaciones $\mathrm{N}$ orte-Sur introduce otro factor político de especial

5. La cohesión interna se mantenía gracias a la confluencia de, por un lado, las estrategias llevadas a cabo en los comités consultivos agrícolas por las organizaciones agrarias integradas en el CO PA (C omité de O rganizaciones Profesionales Agrarias), y, por otro, las de de los correspondientes ministerios de Agricultura nacionales en los comités de gestión. El reconocimiento de la CPE (Coordinadora Campesina Europea) como interlocutor por la Comisión Europea supone la pérdida del monopolio del CO PA, introduciendo un elemento de división y pluralidad en la agricultural policy community. Asimismo, las cada vez más intensas divisiones regionales y sectoriales entre países con ocasión de las reformas de las $\mathrm{O}$ CM s introduce otro elemento de división. 
magnitud. La creciente ola de inmigración procedente de África - por el sur- o de los países ex-comunistas - por el este- está haciendo que se modifiquen las políticas tradicionales de migración en los países de la UE, apostándose, a corto plazo, por una política restrictiva en materia de acogi$\mathrm{da}$ - véase el acuerdo de Schengen - y, a largo plazo, por un aumento de los fondos destinados a la cooperación para el desarrollo de los países de origen. Esta política europea de cooperación con los países en vías de desarrollo supone, de un lado, ampliar las políticas comunitarias y, con ello, aumentar la competencia con la PAC por los recursos del presupuesto de la UE, pero, por otro, supone también la adopción de medidas de apertura de los mercados europeos a productos procedentes de esos países - que son principalmente productos agrícolas y ganaderos, como es el caso de los acuerdos ya vigentes de asociación con $M$ arruecos y T únez dentro del Partenariado Euromediterráneo y los próximos con M ercosur- , lo cual representa un elemento de importantes consecuencias para el sector agrario de los países de la UE.

En cuarto lugar, cabría mencionar como otro importante elemento de cambio político - tal vez el de mayor envergadura por sus implicaciones a medio y largo plazo - el que deriva de la crisis del Estado del bienestar que experimentan los países europeos occidentales y que está obligando a revisar muchos de los principios que han inspirado las políticas públicas, entre ellas los relativos a la política agraria y el desarrollo rural. Los problemas del déficit público y, sobre todo, del desempleo, pero también los relacionados con el deterioro del medio ambiente y la seguridad en el consumo de alimentos, se convierten en elementos a tener en cuenta en la necesaria reformulación de las distintas políticas públicas, entre ellas la reforma de la PAC.

Como ha señalado el documento Por un cambio necesario de la agricultura europea, elaborado por el Grupo de Brugge/Brujas en 1997 (Grupo de Brugge/Brujas, 1997), la futura reforma de la política agraria debe tener en cuenta estos elementos si quiere adquirir una nueva legitimidad ante la ciudadanía. Al haber sido lograda la suficiencia alimentaria - señala dicho documento- , los principios que pueden legitimar socialmente la existencia de una política agraria que demande recursos públicos para garantizar las rentas de los agricultores, son el de su contribución a la generación (o al menos a la no destrucción) de empleo, el de la equidad en la distribución de dichos recursos, y el de su contribución a la protección del medio ambiente y la ordenación del territorio. Estos principios suponen un cambio fundamental en las coordenadas que habían servido de referencia a los agricultores y que habían inspirado las políticas agrarias desde los años cincuenta, siendo también los principios sobre los que debieran construirse las políticas del futuro.

En ese contexto, el debate sobre el contenido de las futuras políticas agrarias y rurales plantea una serie de cuestiones de gran importancia.

La primera sería la de si tiene sentido definir políticas autónomas de desarrollo rural - dotadas de sus propios fondos y gestionadas por instituciones también autónomas- o si no sería más coherente que formen parte, 
como programas operativos, dentro de las políticas más generales de desarrollo regional, dada la tendencia a que las zonas rurales pierdan singularidad como regiones diferenciadas y dado que muchos elementos de los que depende su desarrollo - por ejemplo, las infraestructuras viarias, las redes de equipamientos colectivos o las estructuras de servicios públicos (educativos, sanitarios, etc.) - trascienden el estrecho ámbito de una comarca y escapan al poder de decisión de las instituciones locales.

La segunda cuestión sería la de si - independientemente de que las políticas de desarrollo rural sean autónomas o no de las de desarrollo regionaltiene sentido que la política agraria sea subsumida como parte de una política integral de desarrollo rural marcada por los principios de la diversificación de actividades, la generación de empleo, la fijación de población en el medio rural y la protección del medio ambiente, en el marco más general del desarrollo sostenible, o si no sería más conveniente mantener el carácter autónomo de la política agraria, al tener su propia lógica de funcionamiento y perseguir objetivos diferentes, sobre todo en regiones con un déficit importante de modernización en el sector agrario.

En definitiva, la pérdida de importancia de la agricultura en el conjunto de la economía, la reducción de la población agraria en el conjunto de la sociedad rural, el declive de la influencia de las élites agrarias en los centros de decisión, la diversificación de las actividades en el medio rural, la apertura y liberalización de los mercados, la recuperación de lo local, las nuevas demandas en materia de calidad y de protección ambiental, las restricciones que impone el proceso de construcción europea y, por último, los nuevas fuentes de legitimidad de las políticas públicas para superar la crisis del Estado de bienestar, son algunos de los elementos del contexto de cambio en el que hay que situar los debates sobre el futuro de la sociedad rural europea y sobre el papel que en su desarrollo ha de tener la agricultura.

Ese contexto crea una nueva estructura de oportunidades (económicas, culturales, políticas) para la acción, tanto individual como colectiva de los distintos actores sociales y económicos que residen en el medio rural. No obstante, y lejos de todo determinismo estructural, las acciones de estos actores sólo pueden ser explicadas en la medida en que conozcamos cómo perciben dicho marco de oportunidades y cuál es su capacidad para acceder a los recursos que les ofrece, tarea que abordaremos en el próximo apartado.

\section{D istintas percepciones del cambio en la sociedad rural española}

D e todos los elementos característicos del actual contexto de cambio que afecta a la sociedad rural española, tal vez el de mayor importancia sociológica sea el de la creciente complejidad de su estructura social. En efecto, el proceso de diversificación de las actividades económicas impulsado por los programas de desarrollo local/rural, el aumento de la pluriactividad entre los agricultores, el avance del sector agroalimentario, el ascenso de un importante sector terciario, la cada vez más relevante presencia de servicios públicos liga- 
dos al Estado del bienestar, el fomento de las funciones recreativas y de ocio de los espacios rurales o la promoción de sus funciones ambientales, son factores que convergen todos ellos en hacer de la sociedad rural una sociedad compleja y diferenciada, en la que, junto a los actores tradicionales ligados a la actividad agraria (agricultores, asalariados agrícolas y sus distintas formas asociativas), actúan grupos de intereses no agrarios que imprimen un nuevo dinamismo y que perciben de modo diferente los procesos de cambio en curso.

Incluso dentro del propio sector agrario se pueden observar procesos de diferenciación interna, en función de las orientaciones productivas de las explotaciones y de sus lógicas de gestión, así como de su posición respecto al mercado y respecto a las políticas encargadas de regularlo. El tradicional escenario corporativista basado en el principio de la unidad de intereses de los agricultores, está siendo sustituido por un escenario de pluralidad que se refleja en la diversidad de discursos, estrategias y opciones organizativas existente en el seno del sindical ismo agrario. D entro del sector de los asalariados agrícolas - un sector caracterizado tradicionalmente por mostrar una fuerte cohesión interna en torno a la reivindicación de la tierra y la reforma agraria- se aprecian el ementos importantes de diferenciación entre, de un lado, los asalariados integrados de forma más o menos estable en el mercado laboral (trabajadores fijos y eventuales con relaciones discontinuas, pero regulares), y de otro, los trabajadores temporeros sometidos a un intenso nomadismo laboral y a largos periodos de desempleo; estas diferencias se reflejan, al igual que en el caso de los agricultores, en la diversidad existente dentro del sindicalismo de obreros agrícolas.

A pesar de la evidencia de este escenario de pluralidad de intereses y de complejidad en términos sociales y económicos como rasgo característico de las sociedades rurales de fin de milenio, cuando se observan los trabajos e investigaciones sobre el cambio social nos encontramos todavía con el hecho de que la percepción dominante en estos trabajos continúa siendo la de analizar este proceso de cambio en términos de «crisis», como si fuera un proceso traumático para el conjunto de la población que reside en el mundo rural.

Esta manera de afrontar el análisis de los procesos de cambio en la sociedad rural nos parece parcial y reductora, sólo explicable por el hecho de que gran parte de los científicos sociales especializados en los estudios rurales provienen todavía - sobre todo en los países mediterráneos- de una tradición intelectual o cultural de raíces agraristas. Al centrar de forma preferente sus análisis en los agricultores, la percepción que los científicos sociales trasladan a sus estudios es la que los agricultores tienen sobre el cambio que experimentan las sociedades rurales, un cambio percibido mayoritariamente como crisis al haber modificado de arriba abajo el marco de referencia que guiaba sus estrategias económicas como productores y haber trastocado el sistema de jerarquía social en el que venían posicionándose desde antaño en términos de estatus. 
Afortunadamente, desde hace ya una década, nuevas generaciones de científicos sociales formados en tradiciones intelectuales no agraristas y atraídos por la vitalidad de algunas zonas rurales, vienen incorporando a los estudios rurales enfoques más amplios del cambio social. Al centrar sus estudios en el conjunto de la sociedad rural y no sólo en los agricultores, dan constancia de la complejidad de su estructura social, así como de la pluralidad existente y de la diversidad con que se percibe dicho proceso de cambio por los distintos grupos de intereses. Si bien es verdad que esta nueva generación de científicos sociales, continúa reconociendo que el proceso de cambio es percibido como una crisis traumática por los agricultores, no extiende tal percepción al conjunto de la sociedad rural, ocupándose de analizar cómo lo percibe la población no agrícola. El interés de sus trabajos radica, por tanto, en haber sacado a la luz formas diferentes de percibir el cambio social, mostrando cómo para al gunos grupos sociales éste es percibido como una oportunidad de dinamizar recursos ociosos en el medio rural o como la ocasión de reorientar la utilización del espacio y el territorio en una dirección distinta a la tradicional de la producción agraria.

A continuación se expondrán al gunas ideas sobre las distintas percepciones del proceso de cambio en la sociedad rural y las diferentes formas de interpretar la nueva estructura de oportunidades que dicho proceso ofrece a los actores económicos y sociales que en ella actúan.

\section{La población agrícola ante el cambio de la sociedad rural:}

crisis de identidad y nuevas oportunidades

Tal como han puesto de manifiesto relevantes trabajos de investigación, el cambio que experimenta la agricultura y la sociedad rural en los países industriales avanzados es percibido mayoritariamente por la población agrícola como una crisis de identidad, ya que cuestiona todo su sistema de referencia económico y sociocultural. El sociólogo francés Bertrand H ervieu, en uno de los trabajos más sugerentes de los últimos años (Les champs du futur, París, Boulin, 1993, con versión en español en la Serie Estudios del M APA, 1997), identifica la crisis de identidad que experimentan los agricultores ante el actual proceso de cambio como el resultado de cinco grandes rupturas, que aquí resumimos. En primer lugar, una ruptura de orden demográfico, cuyas principales muestras serían la drástica disminución de la población agrícola y su creciente envejecimiento, convirtiendo a los agricultores en una minoría entre otras. M ientras que para otros grupos sociales ser una minoría no representa ningún trauma por cuanto que siempre lo fueron, para gran parte de los agricultores, sin embargo, es percibida como una pérdida de su tradicional hegemonía en la sociedad rural y como un declive de su influencia a nivel local.

En segundo lugar, una ruptura del modelo de agricultura familiar, debido a que muchas explotaciones agrarias denominadas «familiares» sólo lo son en apariencia, ya que no funcionan como tales en la práctica. La exten- 
sión de la pluriactividad, el hecho de que las rentas de la familia del agricultor ya no dependan exclusivamente de la actividad agrícola y ganadera - es cada vez más frecuente la situación de agricultores en cuya familia uno de los cónyuges trabaja fuera de la explotación- o la proliferación de formas societarias de agricultura en las que se separa el patrimonio de la familia y el de la explotación, serían indicadores de esa ruptura con el modelo tradicional de agricultura familiar, un modelo que ha tenido un papel mítico y cargado de simbolismo para los agricultores de muchas regiones europeas ${ }^{6}$.

En tercer lugar, una ruptura entre agricultura y territorio, de modo que la actividad agraria cada vez se concentra más en determinadas zonas cercanas a los grandes centros de consumo, produciéndose el abandono o la marginalización de otras que quedan excluidas de los circuitos del mercado. En estas últimas, los planes de ordenación territorial se elaboran con apenas el concurso de unos agricultores desarticulados y con escasa capacidad de influencia, con lo que se acaba imponiendo una lógica de utilización del espacio (paisajística y de conservación ambiental) no coincidente con los intereses de la producción agraria. D e ahí que muchos agricultores vean esos planes como una injerencia en lo que ha sido una de sus funciones tradicionales y una amenaza a sus actividades productivas.

En cuarto lugar, una ruptura entre agricultura y alimentación, producida por el hecho de haberse alcanzado la autosuficiencia alimentaria y de haberse liberalizado los mercados agrícolas internacionales. En ese contexto, la sociedad deja de percibir al agricultor a través de su función de productor de alimentos, para percibirlo como una profesión no más importante que otras, y de la que se podría prescindir sin causar graves problemas para el abastecimiento. Su tradicional función - rodeada de simbolismo- de alimentar al conjunto de la sociedad es ahora banalizada, especialmente cuando la mayor parte de los alimentos consumidos proceden de las industrias agroalimentarias.

En quinto lugar, una ruptura entre agricultura y medio ambiente, ocasionada por la extensión de un modelo de desarrollo tecnológico basado en el consumo masivo de inputs químicos y en la utilización de prácticas intensivas que han roto la armonía entre el agricultor y su entorno natural, haciendo que la actividad agraria sea percibida por la opinión pública como una actividad contaminante. Las restricciones por razones ecológicas a la actividad desarrollada por los agricultores son percibidas por éstos como una amenaza a su libertad en el uso de los recursos naturales, más comprensible aún cuando ellos piensan que son los mejores ecologistas y los que mejores conocimientos tienen de los equilibrios existentes en la natural eza (G arrido, 1999).

A estas cinco grandes rupturas habría que añadir una sexta: la ruptura del tradicional ideal unitario que tanto ha servido para cohesionar a los agri-

6. Esta ruptura puede verse para el caso español en el estudio realizado mediante encuesta por C. Gómez Benito y J.J. G onzález (1999). 
cultores, es decir, la idea de pertenecer a un cuerpo social enraizado en un sistema común de valores. La explosión de pluralidad que hoy se observa dentro del propio sector agrario no es más que el reflejo del proceso de diferenciación social y económica que acompaña a la plena integración de la agricultura en el mercado una vez que se van eliminando los tradicionales sistemas públicos de protección. D etrás de apariencias de unidad, como suele ocurrir cuando se adoptan actitudes de defensa frente a terceros, laten profundas diferencias entre los distintos grupos de agricultores (M oyano, 1997), unas diferencias que se manifiestan al menor atisbo de discrepancia a la hora de gestionar los logros conseguidos - el ejemplo de la mesa para la defensa del aceite de oliva, creada por las organizaciones agrarias españolas ante el proyecto de reforma de la $0 \mathrm{CM}$, mantenida a duras penas durante el conflicto y finalmente disuelta por el tema de la modulación de las ayudas, es un caso digno de estudio. Esta ruptura del ideal unitario es vivida todavía en un sentido victimista por ciertos grupos de agricultores - sobre todo, por los que han ejercido la hegemonía desde antaño y se arrogan el deber de velar por ese ideal - , percibiéndola como resultado de la injerencia de el ementos externos que, desde el campo de la política, pretenden socavar la unidad interna del sector agrario.

Asimismo, y más en relación con la población asalariada agrícola - no contemplada por H ervieu en el trabajo que aquí se menciona, dado que éste se centra en la realidad de la sociedad rural francesa, donde es muy escasa la presencia de los asalariados- , se podría añadir otra importante ruptura: la ruptura con la vieja reivindicación histórica del proletariado agrícola en torno al reparto de tierras y la reforma agraria. El cambio de estatus de la agricultura y la propiedad de la tierra como valor simbólico y económico en las sociedades industriales avanzadas desplaza el tema de la reforma agraria del centro de los discursos y reivindicaciones de amplios sectores del proletariado agrícola, que se orientan ahora más hacia la estabilidad en el empleo - y en su ausencia, hacia las demandas en favor de sistemas de protección socialy hacia la mejora de las condiciones laborales en el marco de la negociación colectiva.

Estas rupturas expresan, en definitiva, un sentimiento general izado de crisis de identidad entre los agricultores y los asalariados agrícolas, si bien el modo de afrontar los problemas que les afectan en el actual contexto de cambios no es homogéneo, sino diverso y marcado por la pluralidad, reflejando con ello la realidad de una estructura social agraria cada vez más diferenciada. El nuevo marco de oportunidades es, por tanto, interpretado de modo diferente por los distintos grupos de intereses agrarios, siendo también diferentes sus respuestas, tanto en el nivel de las acciones individuales como en el de la acción colectiva.

a) Respuestas en el nivel de las acciones individuales

En el nivel de las acciones individuales, las respuestas son, en efecto, diversas. D e un lado, se encuentra un sector de pequeños agricultores - forma- 
do por titulares de explotaciones familiares poco competitivas- que han logrado un cierto equilibrio gracias a la combinación de distintas fuentes de renta: las que provienen de la actividad desarrollada en su explotación agraria; las que derivan de las ayudas directas de la PAC; Ias que proceden de la pluriactividad realizada por los miembros de la familia como asalariados en la agricultura 0 en otros sectores, y las que proceden de las distintas prestaciones sociales del Estado (pensiones, subsidios de desempleo, ayudas asistenciales...) (O liveira Baptista, 1998; G ómez Benito y otros, 1999). Para este grupo - que desempeña un papel fundamental en el dinamismo y vitalidad de muchas zonas rurales de la Europa mediterránea y que sería condenado a la exclusión si se aplicara en esas zonas el modelo agrícola centroeuropeoel actual contexto de cambio le ofrece nuevas oportunidades en la medida en que el Estado continúe estando presente a través de sus políticas públicas, ya que sin tales mecanismos de protección difícilmente podrían reproducirse socialmente como agricultores. Su percepción del cambio no puede decirse que sea traumática, ya que su situación actual no es peor que la que tenían en la anterior estructura de oportunidades, donde la emigración era su principal salida.

D e otro lado, se encuentran agricultores con explotaciones de tamaño medio y grande, que se limitan a seguir una estrategia conservadora de recogida de las subvenciones públicas provenientes de la PAC, subvenciones que, junto a los ingresos obtenidos por la venta de sus producciones en el mercado, les ha venido garantizando su reproducción social con el mínimo coste y sin apenas riesgo. El carácter traumático del cambio para este grupo radica en la perspectiva, cada vez más real y cercana, de que tales subvenciones se recorten e incluso que desaparezcan, y en la amenaza con que viven la apertura de los mercados, una apertura para la que no se sienten preparados. Asimismo, este grupo, del que, hasta hace bien poco, se reclutaban las élites de muchas comunidades rurales españolas, es el principal afectado por la pérdida de influencia de los intereses agrarios en la vida política y económica local, percibiendo como una injerencia en los asuntos de la comunidad agraria el que los nuevos grupos en ascenso - especial mente los grupos ecologistas- participen en las decisiones que afectan al destino de los espacios rurales. Se produce en este grupo una especie de repliegue corporativista, convirtiendo el victimismo en su discurso, un discurso que, en situaciones límite, es caldo de cultivo para proclamas destinadas a satanizar la política y los políticos - si provienen de Bruselas, tanto mejor- y a demonizar el proceso de mundialización y de apertura de mercados - percibido como un proceso impuesto por las multinacionales. Es éste, sin embargo, un discurso cargado de ambigüedad, ya que, al mismo tiempo que reclama para ellos el proteccionismo estatal, rechaza el control ejercido por los organismos públicos y defiende un modelo basado en el derecho a la propiedad privada y a ejercer su libertad como empresarios.

N o obstante, junto al sector marcado por el conservadurismo se observa un sector innovador - reclutado de los diferentes segmentos de la estructu- 
ra social agraria - que viene introduciendo cambios importantes en sus explotaciones. Así, encontramos agricultores con explotaciones de tamaño medio y grande que optan por nuevas orientaciones productivas - por ejemplo, cultivos bioenergéticos o de aprovechamiento en la industria textil o farmacológica - y que aprovechan las oportunidades que les ofrecen las nue vas tecnologías para mejorar la gestión de sus explotaciones. También encontramos agricultores que desarrollan actividades no agrarias en sus explotaciones (turismo rural, cinegética, forestación, granjas escuela, etc.) como fuentes complementarias de renta en el marco de las nuevas políticas de desarrollo rural. Asimismo, se observan interesantes iniciativas de agricultura sostenible en la utilización de los recursos naturales, ya sea con el fin de explotar de forma más equilibrada los suelos agrícolas, o con la finalidad de utilizar de modo más racional los insumos químicos para reducir los costes de producción, siendo diverso el origen de las respuestas que dan los agricultores. En efecto, pueden ser respuestas inspiradas en principios de racionalidad ecológica basados en una nueva ética ambiental (Thompson, 1996), al ser ellos los primeros en comprobar el deterioro que los modelos de agricultura intensiva han causado sobre el medio ambiente, pero también pueden estar guiadas por criterios de un «capitalismo verde» preocupado por la degradación de los recursos naturales en tanto que factores de producción (C liment, 1998). D e igual modo, pueden ser simples respuestas pragmáticas al nuevo marco de oportunidades creado por los cambios en los hábitos de consumo de la población - como ocurre con el emergente mercado de productos ecológicos- o por los incentivos de los programas agroambientales de la UE, un marco en el que los agricultores ven la posibilidad de obtener fuentes complementarias de renta (W hitby, 1996; G arrido y M oyano, 1998).

Este sector innovador se muestra consciente de la complejidad de los cambios que experimenta la agricultura y de su nueva posición - ya no hege mónica - en las agendas públicas, respondiendo a ese contexto con actitudes no corporativistas ni de repliegue e involución, sino de apertura a las nuevas oportunidades que se les ofrece. $M$ ás que protección, reclaman del sector público información y formación para ayudarles a adaptarse a la nueva situación de mercados abiertos, así como incentivos para abordar proyectos de reconversión en sus explotaciones. D esde el punto de vista de sus relaciones sociales, muestran actitudes favorables a implicarse en proyectos conjuntos con otros grupos de intereses, ya sea para experimentar cambios en sus prácticas agrícolas - por ejemplo, con técnicos o investigadores científicos en el campo de la agronomía, como es el caso de la experiencia Agrofuturo- , para contribuir a la protección del medio ambiente - por ejemplo, colaborando con la Administración pública en las campañas de prevención de incendios- , o para implicarse en la conquista de nuevos mercados - participando en proyectos de inversión en la agricultura de otros países, como M arruecos.

En lo que respecta a los asalariados agrícolas, las respuestas se orientan en varios sentidos, no necesariamente excluyentes. Por un lado, en estabilizar su situación en el mercado laboral, mediante el aprovechamiento de las 
oportunidades surgidas en los distintos sectores productivos accediendo a contratos fijos o discontinuos. Por otro, en aprovechar los sistemas de protección social en los que se combinan los subsidios con planes públicos destinados a fomentar el empleo en las zonas rurales (por ejemplo, el caso del Plan de Empleo Rural). Y, finalmente, en optar por itinerarios de emigración temporera de acuerdo con la estacionalidad de la recolección y demás labores agrícolas.

b) Respuestas en el nivel de la acción colectiva (cooperativas y sindicatos)

En el sector agrario, las formas asociativas desempeñan un papel fundamental, tanto al ser ejes de articulación económica (las cooperativas, principalmente), como al actuar de centros de vertebración de intereses para la representación sindical (tal es el caso de las organizaciones profesionales agrarias y de los sindicatos de trabajadores). A través de la fuerte presencia del cooperativismo en el sector agrario - con su extensa red de cooperativas por toda la geografía rural española - y de la elevada capacidad de movilización que muestran las organizaciones profesionales y sindicales, el movimiento asociativo ejerce una importante influencia en las actitudes y en el comportamiento de los agricultores y trabajadores agrícolas, al tiempo que se erige en un importante actor intermedio en la aplicación de la política agraria y rural. Sus dirigentes son líderes de opinión cuyo posicionamiento respecto a los temas relacionados con la agricultura y el mundo rural tiene resonancia en los medios de comunicación y se convierten en punto de referencia para los agricultores y asalariados agrícolas. Por ello, es importante analizar cómo se percibe el actual proceso de cambios desde el movimiento asociativo y cuáles son las respuestas que se dan en este nivel de la acción colectiva, dada la incidencia que tiene en la definición de las preferencias de los agricultores y los asalariados agrícolas.

b.1) En lo que se refiere al cooperativismo agrario, se observa una percepción bastante homogénea del cambio, reafirmán dose la tendencia de las cooperativas a ir profesionalizando su actividad e introducir criterios empresariales en su gestión para responder al nuevo contexto de competitividad. Si tomamos como ejemplo la CCAE, que es la organización en donde converge la casi totalidad del cooperativismo agrario español (Entrena y M oyano, 1997), su discurso es claramente empresarial - las cooperativas como empresas que han de buscar el máximo de rentabilidad en los mercados- , quedando bastante diluido el viejo ideal mutualista. Su modelo organizativo, aunque formalmente vertebrado a través de estructuras horizontales basadas en el territorio, viene marcado por la presencia cada vez más importante de estructuras vertical es que articulan los distintos subsectores agrícolas y ganaderos. La cohesión sobre la base de los intereses económicos compartidos en torno a un determinado subsector o rama de producción, predomina sobre el viejo principio de cohesión basado en un sentimiento de pertenencia a un movimiento social. 
Para el cooperativismo agrario, la nueva estructura de oportunidades que ofrece el actual proceso de cambio es percibida como un reto que debe ser afrontado con profundas reformas, tanto en la legislación como en el propio movimiento cooperativo, reformas que liberen a las cooperativas de los viejos corsés y las prepare para competir en el contexto de mercados abiertos que cada vez más se les presenta como una realidad insoslayable. La flexibilización del principio de puertas abiertas, del que regula las operaciones con terceros e incluso del de la gestión democrática, se convierte en doctrina dominante dentro del cooperativismo agrario español. Los viejos objetivos de incidir en los procesos de cambio social y de contribuir a mitigar los efectos perversos del mercado, han sido sustituidos por los más prosai cos de diversificar actividades y conquistar nuevos espacios comerciales, ya que con ello aspiran a mejorar de manera más tangible la renta de los agricultores asociados. Eso explica que las cooperativas hayan relegado a un segundo plano - cuando no abandonado- aquellas actividades de promoción sociocultural que les daban una cierta singularidad en sus primeras etapas de formación y se estén centrando ahora en actividades de carácter economico, tanto agrarias como no agrarias. La lógica de los mercados y la competitividad, en detrimento del viejo mutualismo cooperativo basado en la solidaridad, ha acabado por imponerse en su seno, al igual que en el resto del cooperativismo agrario europeo (Bager, 1997), asumiendo como modelo a seguir los criterios de burocracia organizativa y de profesionalización y división jerarquizada de las tareas típicos de la economía empresarial, aunque sea revestido del calificativo de economía social.

Sobre los temas que son objeto de debate político en torno a la futura política agraria - la modulación de las ayudas y la relación entre políticas agrarias y de desarrollo rural- , las cooperativas no suelen expresar opiniones como entidades colectivas, ya que la heterogeneidad de sus bases sociales las Ileva a evitar posicionamientos que podrían provocarles conflictos internos; de ahí que se comporten como asociaciones de naturaleza apolítica. La confederación C CAE procura también mantener un difícil equilibrio entre las distintas cooperativas asociadas, por lo que sólo manifiesta sus opiniones institucionales en temas que afectan directamente al cooperativismo - por ejemplo, con ocasión de alguna reforma de la legislación, como ocurrió con el tema de la ley de interprofesiones 0 , más recientemente, con la aprobación de la nueva ley de cooperativas- o en temas más generales en los que hay un consenso en el sector - la movilización sobre el proyecto de reforma de la O CM del aceite de oliva- . En otras situaciones de mayor disenso procura adoptar posicionamientos eclécticos y dejar el campo de disputa a las organizaciones sindicales.

b.2) A diferencia de la uniformidad que se observa en el seno del cooperativismo respecto al proceso de cambio, la pluralidad es la norma en el sindicalismo agrario - con tres organizaciones (ASAJA, COAG y UPA) mayoritarias- , pudiéndose distinguir dos tipos de respuestas (M oyano, 1997). 
En primer lugar, una respuesta de tipo «empresarial», promovida por las organizaciones cuyas estrategias reflejan mayoritariamente los intereses de agricultores con explotaciones de tamaño mediano y grande - ASAJA sería la organización que mejor refleja este tipo de respuesta, aunque también agrupen a muchos pequeños agricultores- . En esta respuesta, se propone una mayor integración con el sector de las industrias agroalimentarias a través de estructuras de tipo interprofesional dentro de cada filiére; se apuesta por un modelo sectorial para la vertebración de los intereses agrarios, en detrimento de los model os tradicional es de carácter multisectorial; se impulsa la incorporación de los agricultores a las nuevas tecnologías de gestión empresarial, y se aboga por seguir avanzando en el proceso de modernización productiva de las explotaciones agrícolas aunque sea desde coordenadas distintas de las que guiaron la modernización de los años sesenta. M ás allá de lo que es la batalla sindical en torno a cuestiones más coyunturales, un análisis detallado de las posiciones adoptadas por este tipo de organizaciones en sus asambleas y congresos nos permite observar su preocupación por los riesgos que supone centrar en exclusiva las rentas de los agricultores en la recolección de subvenciones públicas. Tal preocupación la basan en el hecho de que estas subvenciones son cada vez más cuestionadas en el conjunto de la UE y menos seguras ante las reformas de la PAC en curso, y de que la forma en que son distribuidas - sin contrapartidas- deslegitiman socialmente las funciones del agricultor como empresario.

Actualmente, en torno al tema de la modulación de las ayudas públicas procedentes de la $U E$, estas organizaciones empresariales experimentan un fuerte debate interno. De un lado, un grupo de sus dirigentes considera inevitable la introducción de criterios de diferenciación en el reparto de las ayudas públicas - sobre todo después de que la Agenda 2000 haya incluido este tema entre sus propuestas- y considera un error oponerse a ello. A puestan por tomar la iniciativa anticipándose a las organizaciones de pequeños agricultores y proponiendo sistemas de modulación que tengan en cuenta, entre otros factores, la inversión realizada por el agricultor en su explotación; asimismo, proponen que el ahorro originado con la aplicación de tales sistemas pueda ser destinado a financiar programas de modernización en cada sector productivo, para mejorar la eficacia competitiva de las explotaciones y fortalecer las estructuras de comercialización en el actual contexto de mercados abiertos. D e otro lado, dentro de las organizaciones empresariales se encuentran también grupos que se oponen radicalmente a los sistemas de modulación por considerar una incongruencia introducir criterios de equidad en políticas de mercados, cuando los objetivos sociales que se persiguen con dichos sistemas se podrían lograr precisamente a través de las políticas fiscales de carácter distributivo. Estos grupos apuestan por estrategias obstruccionistas para impedir 0 , al menos, dificultar la puesta en marcha de los sistemas de modulación, esgrimiendo como argumentos el de la complejidad técnica de su aplicación, el de que con tales sistemas España perdería parte de la cantidad global de recursos que ahora recibe de la U E a través de las 
ayudas directas, o el de que la modulación incitaría al fraccionamiento de las grandes explotaciones agrarias perdiéndose competitividad en la agricultura española.

Respecto al debate en torno al estatus de las futuras políticas agrarias, abogan por que éstas conserven su estatus como políticas autónomas no debiendo ser subsumidas en las políticas de desarrollo rural. Para estas organizaciones de tipo empresarial que representan los intereses de agricultores con explotaciones potencialmente competitivas en mercados abiertos, la política agraria debería continuar guiándose por la lógica de la producción, aplicando programas que incentiven a los agricultores en la mejora de sus estructuras y en su integración en redes comerciales más amplias, al igual que hicieron las políticas de modernización de los años sesenta. La futura política agraria debería, por tanto, continuar impulsando la modernización del sector - especialmente en las regiones mediterráneas, que presentan un déficit importante de modernización respecto a las regiones centroeuropeas- para hacerlo más competitivo. Su integración en las políticas de desarrollo rural significaría supeditarla a una lógica social basada en la generación de empleo, lo que no puede ser objetivo exigible a una agricultura moderna que se ha de caracterizar precisamente por el aumento de productividad y la reducción de población activa.

Finalmente, en lo que se refiere a la política agroambiental, estas organizaciones de tipo empresarial no se oponen a ella, si bien la colocan en un lugar secundario dentro de sus preocupaciones, que vienen marcadas, como se ha señalado, por la competitividad en los mercados y por las relaciones entre agricultura e industria. Los problemas de la relación entre agricultura y medio ambiente se plantean en términos de sustentabilidad económica, al percibirse que el deterioro de los recursos naturales puede amenazar la disponibilidad del medio ambiente como factor de producción para su uso agrícola - haciendo suyo el ya comentado discurso de «capitalismo verde».

En segundo lugar, se puede distinguir otro tipo de respuesta, que podríamos denominar neocampesina por resaltar los valores de un mundo rural renovado social y culturalmente, en el que la agricultura de tipo familiar (una especie de campesinado moderno) debe continuar ocupando un lugar central como elemento dinamizador. Esta respuesta, distinta de la empresarial, es protagonizada por las organizaciones que representan los intereses de los pequeños agricultores - UPA y COAG son las que mejor la expresany propone políticas integrales que no sólo contemplen los aspectos productivos de la agricultura, sino que también fomenten la diversificación de actividades; asimismo, apoya los modelos horizontales para la articulación de los intereses agrarios, impulsando la colaboración con otros grupos de intereses que actúan en la sociedad rural - los ejemplos de la Plataforma Rural promovida desde COAG o del acuerdo de colaboración de UPA con la asociación ecologista SEO son ilustrativos- en detrimento de los modelos verticales basados en la articulación sectorial en el marco de la filiére, y apuesta finalmente por una firme intervención del Estado como regulador de los 
desequilibrios del mercado e impulsor de las formas asociativas para la defensa de los pequeños agricultores.

Respecto al tema de la modulación, existe unanimidad en estas organizaciones no sólo sobre la conveniencia, sino también sobre la necesidad, de aplicar criterios diferenciadores en el reparto de las ayudas públicas. Para estas organizaciones, la modulación es necesaria porque, ante las restricciones cada vez mayores que se presentan a la hora de disponer de recursos para regular las distintas 0 C M s, las ayudas deben concentrarse en los segmentos de explotaciones con mayores dificultades para ser competitivas, si se desea que los pequeños agricultores no abandonen su actividad. Pero consideran que la modulación es también conveniente para que la política agraria recupere su legitimidad ante el conjunto de la sociedad, que ve con perplejidad, cuando no con indignación, que determinados grupos de agricultores amasen grandes fortunas mediante la recolección de unas ayudas públicas que, financiadas con cargo a los contribuyentes, se conceden sin contrapartida al guna y sin una clarajustificación. C riterios como la generación de empleo, el nivel de renta, la residencia en el medio rural o la protección ambiental, son algunos de los que proponen estas organizaciones para aplicar los sistemas de modulación.

Respecto al estatus de las futuras políticas agrarias, abogan por políticas integrales de desarrollo rural en las que se incluyan acciones destinadas al fomento de las actividades agrarias en las explotaciones de tipo familiar, no con criterios de competitividad, sino con una lógica de sustentabilidad social para evitar la exclusión de los pequeños agricultores, ya que reconocen el papel fundamental que desempeñan en el dinamismo de las zonas rurales. En este mismo sentido integrador sitúan a las políticas agroambientales, en las que ven nuevas oportunidades para complementar las rentas agrarias valorando sus posibilidades para una nueva integración de los agricultores en la sociedad y para una nueva legitimidad de la política agraria (G arrido, 1999).

b.3) En relación con el sindicalismo de obreros agrícolas, y tomando como eje de análisis al gunos de los el ementos característicos del contexto de cambio, a saber: la pérdida del valor económico y simbólico de la propiedad de la tierra, la pérdida de identidad del movimento jornalero, la mejora de las condiciones laborales en el marco de la negociación colectiva y los planes públicos de empleo rural, pueden apreciarse dos tipos de respuestas, diferenciadas en razón de sus discursos y estrategias. U na respuesta «adaptativa y reformista», representada en sus grandes líneas por Comisiones 0 breras del Campo y la FT T, y otra de tipo «rupturista y radical», asumida por el SOC.

La respuesta «reformista» se caracteriza por haber modificado sustancialmente su posición respecto al tema de la propiedad de la tierra para adaptarse al nuevo contexto de cambio. D e haber rechazado frontalmente la gran propiedad terrateniente, no reconociéndole ninguna función social y exigiendo 
del Estado medidas expropiatorias para actuar contra ella, ha pasado a no cuestionarla como principio, distinguiendo entre grandes agricultores que utilizan adecuadamente los recursos disponibles y ejercen una función socialmente reconocida, y aquellos otros que infrautilizan de modo flagrante los recursos y que deben ser objeto de medidas penalizadoras. D e acuerdo con este planteamiento, critican el sistema de ayudas directas de la PAC a los agricultores por ser un sistema que, al estar desvinculado de la producción y la generación de empleo, fomenta el absentismo empresarial y beneficia a los grandes agricultores.

Por su parte, la respuesta «radical» cuestiona de raíz la actual estructura de la propiedad de la tierra, denunciando incluso su carácter ilegítimo por entender que ha sido fruto de las expoliaciones que han sufrido históricamente los campesinos y, más concretamente, de la usurpación de sus derechos sobre la tierra que tuvo lugar durante los procesos desamortizadores del siglo XIX. Por ello, la reforma agraria es todavía analizada como el pago de una deuda histórica, siendo el carácter ilegítimo de la actual estructura de la propiedad de la tierra lo que justificaría la aplicación de medidas expropiatorias sobre las grandes explotaciones, independientemente de que utilicen bien o mal los recursos de que disponen?.

En lo que respecta al tema de la posición social del proletariado agrícola, ambas respuestas son claramente diferentes. La «reformista» acepta la gradual reconversión del movimiento jornalero y reivindica su equiparación como asalariados al conjunto de la población trabajadora en cuanto a condiciones de trabajo, mejoras salariales y prestaciones sociales, lo que está en sintonía con el hecho de que tanto la FT T como C C.O O . del Campo estén integradas en confederaciones sindicales de carácter intersectorial ${ }^{8}$. Por su parte, la respuesta «radical» sitúa al movimiento jornalero en el centro de los problemas del mundo rural, planteando que reivindicar su identidad y supervivencia significa hacer una crítica de fondo (de raíz) al modelo de desarrollo vigente; de ahí que amplíe su discurso hacia temas no relacionados directamente con el rol del jornalero como trabajador agrícola, sino con su posición social en el conjunto del mundo rural. Esto explica, por ejemplo, que el SOC se mantenga como sindicato no integrado en las centrales sindicales mayoritarias y que incorpore entre sus reivindicaciones los problemas de las condiciones de vida en las comunidades rurales o el deterioro del medio ambiente por el modelo productivista de desarrollo. En sintonía con este discurso, el SO C, lejos de responder a la tendencia de los sindicatos reformistas de ir asimilando sus bases sociales a las del resto del movimiento obre ro, incorpora en su seno a otras fuerzas y movimientos sociales presentes en

7. Este planteamiento explica la oposición que el SO C mantuvo contra la actual ley andaluza de Reforma Agraria.

8. La firma del AEPSA por parte de estos dos sindicatos, y la campaña de movilización llevada a cabo por ellos para lograr la inclusión de los asalariados agrícolas en el régimen gene ral de la Seguridad Social, es un buen indicador de su discurso reformista. 
el mundo rural (jóvenes desempleados, grupos ecologistas...), aunque no tengan la condición de asalariados, habiendo modificado recientemente su antigua denominación por la de «sindicato de obreros del campo y de los trabajadores rurales»»?

En relación con el tema de la negociación colectiva, los sindicatos de tipo «reformista», C COO y FTT, se caracterizan por apoyar su participación en las mesas de concertación social para tratar con los representantes del empresariado agrícola las condiciones de trabajo y los niveles salariales de la población jornalera. En este sentido, y en concordancia con su discurso ideológico, estos sindicatos han aceptado el modelo neocorporativista de concertación por entender que los intereses de la base social que representan, formada sobre todo por asalariados fijos y eventuales, pueden ser bien defendidos en el marco de las negociaciones colectivas con las organizaciones empresariales, sin que ello implique el abandono de la movilización como instrumento de presión.

Por su parte, el SOC se ha negado sistemáticamente a participar en dicho marco de relaciones laborales, ya que, de acuerdo con su posición ideológica, los intereses del movimiento jornalero no son identificables sólo con las mejoras salariales, sino que su contenido afecta a otros problemas existentes en el medio rural. En opinión de este sindicato, la reivindicación y defensa de esos intereses generales debe hacerse con otros métodos de lucha y dotarse para ello de unas estructuras organizativas descentralizadas y en estrecha conexión con la base social a la que se dirigen. Ello explica, por ejemplo, la escasa formalización de dichas estructuras organizativas y la utilización sistemática de la movilización como instrumento de presión, movilización expresada en las numerosas marchas u ocupaciones de fincas a las que nos tiene acostumbrados este sindicato.

Por último, en relación con los planes públicos de empleo rural y los sistemas de protección por desempleo, se produce una diferencia importante. $M$ ientras que la respuesta «reformista» consiste en aceptar que esos planes y sistemas públicos de protección se dirijan en exclusiva a los trabajadores agrícolas, debiéndose previamente clarificar los censos para definir con precisión el colectivo de los posibles beneficiarios, la respuesta «radical» reivindica que tales planes se extiendan al conjunto de la población desempleada en el medio rural, tenga o no vinculación con el sector agrario.

En definitiva, dentro del propio sector agrario se observa una explosión de pluralidad que se refleja en las diferentes respuestas - tanto individuales, como colectivas- de los agricultores y asalariados y de sus respectivas organizaciones a los nuevos problemas que les afectan. El actual proceso de cambio es percibido como crisis por el conjunto del sector agrario, pero las respuestas para salir de ella son diversas, como corresponde a una estructura social cada vez más compleja y diferenciada.

9. Un excelente análisis de la génesis y desarrollo del SO C puede verse en M orales (1997). 
El cambio, como nuevo marco de oportunidades para la población rural no agrícola

$\mathrm{H}$ asta ahora se ha preguntado muy poco a la población rural no agrícola sobre cómo percibe el cambio que experimenta la agricultura y el mundo rural español. Tal como se ha señalado más arriba, las reflexiones sobre el cambio en el mundo rural han venido marcadas, sobre todo, por la tradición agrarista de muchos investigadores sociales, procedentes en su mayoría de las escuelas de ingenieros agrónomos 0 de la propia Administración pública del M inisterio de Agricultura - principalmente, del Servicio de Extensión Agraria y del extinto IRYDA - y que se articulaban institucionalmente en el seno de la Asociación Española de E conomía y Sociología Agraria (AEEySA). Los agricultores han sido el grupo privilegiado de referencia para explicar el cambio de las sociedades rurales en España, por lo que no es sorprendente que la percepción de éstos haya sido hasta hace poco la dominante en los estudios rurales.

D esde hace unos años, está emergiendo una nueva generación de investigadores sociales (sociólogos, geógrafos, antropólogos) procedentes de las distintas facultades universitarias, una generación que no es de formación agrarista y que comienza a analizar el cambio en la sociedad rural a partir de las percepciones que de dicho proceso tienen los grupos no relacionados con la actividad agraria. En los tres últimos congresos españoles de sociología (1992, 1995 y 1998), organizados por la FES (Federación Española de Sociología), más de la dos terceras partes de los trabajos presentados en el grupo de sociología rural trataron de temas relacionados con el desarrollo local, el medio ambiente, el turismo rural, las artesanías, la pesca, la minería, la gestión de los parques naturales, etc., temas todos ellos que, si bien no excluyen a los agricultores, sí pueden considerarse temas emergentes no relacionados con la actividad agraria. Asimismo, dentro de la FES se ha creado un grupo permanente (Research Committee) de Sociología Rural en el que, junto a la nueva generación de investigadores sociales, se han integrado los antiguos sociólogos de formación agrarista, una vez convertida la antigua AEEySA en la actual Asociación Española de Economía Agraria, ya orientada definitivamente a los estudios de economía aplicada. D e este modo se inicia un interesante proceso de rearticulación institucional de la sociología en el marco de la FES, si bien con una perspectiva multidiscipinaria de los estudios rurales en colaboración con las disciplinas de la antropología, la geografía, el dere cho y la historia agraria.

Lo importante a los efectos del hilo argumental de este artículo, es que en los trabajos de esta nueva generación de sociólogos se pone de manifiesto una percepción del cambio muy diferente de la de los agricultores, no viniendo acompañada de la componente traumática de crisis de identidad que suele caracterizar a éstos últimos, sino de una componente de dinamismo que debe ser destacada. En estos trabajos se señala que, para muchos grupos de la población no agrícola, el actual proceso de cambio ofrece importantes 
oportunidades de dinamización del medio rural y abre posibilidades para un mejor aprovechamiento del espacio y el territorio de acuerdo con las nuevas demandas de la sociedad.

Así, se destaca, por ejemplo, que los programas de desarrollo local/rural, sean o no canalizados a través de los programas LEADER o PRODER, han propiciado la emergencia de nuevos actores que se convierten en protagonistas de la vida económica y social en las comunidades rurales. N uevas iniciativas empresariales al amparo de esos programas, pero también la proliferación de técnicos y agentes de desarrollo local, introducen un dinamismo en las zonas rurales que hacen percibir los actual es procesos de cambio de modo diferente a como los perciben los agricultores. En algunos casos, tales programas están propiciando incluso la incorporación de los grupos de agricultores más dinámicos a los proyectos de desarrollo, ofreciéndoles la posibilidad de diversificar sus actividades e introducir innovaciones en la forma de gestionar sus explotaciones. Estos actores del desarrollo rural/local, hasta ahora dispersos en sus acciones y circunscritos al ámbito de su correspondiente programa de desarrollo, comienzan a articularse en estructuras asociativas, no sólo para intercambiar sus experiencias, sino para emprender acciones más amplias y participar como nuevos actores colectivos en los foros nacionales e internacionales en los que se dirime el contenido de las políticas de desarrollo rural. La asociación ARA (que agrupa a los presidentes de los grupos de acción local LEADER y PRO DER de Andalucía) es un ejemplo de estas iniciativas. Para estos actores, las zonas rural es presentan singularidades que las diferencian de otras zonas, por lo que abogan en favor de que las políticas de desarrollo rural se mantengan como políticas autónomas - con sus propios fondos- y no sean subsumidas como programas dentro de las de desarrollo regional. Sin embargo, critican el sesgo agrarista que han tenido las políticas de desarrollo rural, proponiendo que no se canalicen, como hasta ahora, a través de los departamentos de agricultura, sino que sean implementadas por organismos interdepartamentales de carácter horizontal, con capacidad para integrar las distintas acciones contempladas dentro de ellas. No aceptan, por ejemplo, que los programas LEADER y PRO DER continúen siendo canalizados a través del M inisterio de Agricultura y de las consejerías de ese mismo área en las comunidades autónomas, puesto que la mayor parte de las acciones que contemplan no son agrarias y sus protagonistas no son agricultores.

Junto a esos actores del desarrollo local/rural, otros nuevos actores emergen al amparo de los sectores vinculados al Estado del bienestar (sanidad, educación, servicios sociales), convirtiéndose en sectores dinámicos que definen el futuro del mundo rural de modo diferente a como ha sido tradicional y que, en muchas ocasiones, se implican directamente en los programas de desarrollo, bien a título personal o a través de la institución a la que pertenecen. Su presencia en los pueblos es cada vez mayor, sobre todo después de que la mejora de las comunicaciones y de la calidad de vida en las zonas rurales propicia que estos grupos de profesionales opten por residir en los núcleos en donde trabajan, comenzando a romperse la tendencia, hasta hace muy poco 
dominante, a salir de ellos conforme finalizaban su jornada laboral. La importancia de estos sectores no puede ignorarse, por cuanto que muchas veces es mayor la incidencia de las políticas educativas o sanitarias sobre el futuro de las zonas rurales - al diseñar los mapas de centros escolares o de salud-, que los propios programas de desarrollo rural.

Finalmente, la consideración de las funciones de ocio y recreativas de los espacios rurales promueve también la presencia de una población de origen urbano (residentes en periodos de vacaciones o de fin de semana, excursionistas, practicantes de senderismo y deportes de naturaleza... ), que, al tiempo que recuperan antiguas tradiciones del folklore rural, acaban imponiendo pautas de comportamiento típicas de la cultura urbana (movidas nocturnas juveniles, discotecas, utilización masiva del automóvil... ) (Entrena, 1998). Asimismo, la instalación de jóvenes en las nuevas modalidades de agricultura - por ejemplo, la agricultura ecológica- , frecuentemente coordinados con sectores del movimiento ecologista local, introducen una consideración no agrarista en la explotación de los recursos naturales, distanciándose del discurso tradicional de los agricultores o provocando situaciones de división interna dentro del sector agrario local.

Para todos estos grupos, el actual contexto de cambios ofrece oportunidades para la dinamización del mundo rural (García Sanz, 1996), procurando influir en las decisiones que se toman a nivel local a través de su participación en la política municipal. C ada vez es más frecuente que entre los concejales que componen los plenos de los ayuntamientos en zonas rurales se encuentren personas procedentes de esos sectores (médicos, maestros, asistentes sociales, monitores de grupos ecologistas... ), erigiéndose, junto a profesionales y empresarios de sectores no agrarios, en las nuevas élites locales.

No obstante, estos grupos adoptan respuestas dispersas y escasamente articuladas al nuevo marco de oportunidades, y constituyen una muestra de la diversidad de intereses que existe en el mundo rural de hoy, una diversidad que debe continuar siendo objeto de investigación por parte de los científicos sociales para ampliar nuestro conocimiento sobre la dinámica social y económica de la sociedad rural española. En ese contexto, los investigadores tienen ante sí un interesante caldo de cultivo para analizar si se está produciendo o no la emergencia de una nueva identidad «rural», una identidad ya no marcada por su dimensión agraria exclusivamente, sino como una síntesis de las distintas actividades y profesiones, incluyendo la agricultura, que confluyen en el hecho de desarrollarse en núcleos de población de tamaño pequeño o mediano y caracterizados por una especial conexión con el espacio y el territorio. La cuestión a dilucidar es si tal confluencia entre las identidades de los distintos grupos que componen la sociedad rural es lo suficientemente fuerte como para que se pueda hablar de la existencia de una nueva identidad «rural», o si por el contrario lo que existe es una dispersión de identidades sin conexión entre sí y sin conciencia alguna de pertenecer a una comunidad cultural ni a un área de intereses compartidos. 


\section{Conclusiones}

El análisis de los procesos de cambio en la sociedad rural permite contribuir a un mejor conocimiento de las dinámicas sociales bajo contextos de nuevas estructuras de oportunidades. En esos contextos, los actores sociales aprovechan tales oportunidades en un sentido o en otro según su particular percepción del proceso de cambio y su particular forma de interpretarlo, desarrollando acciones tanto en el nivel individual como colectivo para afrontar los problemas que les afectan. D el análisis efectuado en este artículo, pueden extraerse varias conclusiones.

En primer lugar, que, en el contexto actual de globalización y de reforma de las tradicionales políticas de protección, la sociedad rural deja de ser un mundo aparte para convertirse, cada vez más, en un ámbito abierto a las influencias de la sociedad más amplia, reproduciéndose en ella el dinamismo y la diversidad de intereses característicos de las sociedad abiertas.

En segundo lugar, que es comprensible que los agricultores perciban el proceso de cambio como una crisis de identidad, ya que dicho proceso está transformando radicalmente el marco de referencia en el que habían orientado sus acciones en las últimas cuatro décadas. N o obstante, la gradual integración de la agricultura en los mercados, una vez sustituido el paraguas proteccionista de la política agraria, genera efectos de diferenciación económica y social entre los propios agricultores, reflejándose en las formas diferentes que muestran a la hora de percibir el contexto de cambio y en sus distintas respuestas. El principio de la unidad - más simbólico que real - del sector agrario ha sido sustituido por el de la pluralidad, como lo prueba la diversidad existente en el seno del sindicalismo.

En tercer lugar, que los asalariados agrícolas experimentan una profunda modificación de su sistema de referencia, tanto simbólico como social, debido al cambio de estatus de la agricultura como actividad y de la propiedad de la tierra como recurso económico, y a las reformas producidas en el mercado laboral y en los derechos de los trabajadores. Ante esta situación, la respuesta dominante es la de adaptarse al nuevo contexto de cambios y aprovechar del mismo las oportunidades que ofrece para la mejora de las condiciones laborales de los asalariados agrícolas. N o obstante, se observan en zonas muy localizadas respuestas más radicales que mantienen con vigor la bandera de la reivindicación de tierras y que buscan una nueva identidad en el marco de los valores emergentes en el mundo rural.

En cuarto lugar, que, junto a los agricultores, se consolida en la sociedad rural grupos de la población con actividades no directamente relacionadas con la agricultura, que imprimen un nuevo dinamismo al provenir de ámbitos culturales y sistemas de valores distintos a los que han sido dominantes en el mundo rural. La estructura social se hace más compleja y las relaciones entre sus distintos grupos se hacen más dinámicas: en unos casos, mediante la cooperación, pero en otros mediante el conflicto por la definición de los espacios rurales. 
En quinto lugar, que, en un contexto sociocultural caracterizado por la autosuficiencia alimentaria, por el avance de valores posmaterialistas en la población, por la demanda de un modelo de desarrollo sostenible, por la reafirmación de lo local frente a la globalización y por la necesidad de re orientar el papel del Estado del bienestar, los espacios rurales son definidos de modo plurifuncional. Ello tiene importantes efectos sobre los principios que han de inspirar la reforma de las políticas públicas y más particularmente de la política agraria, una política cuya finalidad de explotar con fines al imentarios los recursos naturales ha sido su fuente de legitimidad. En el nue vo contexto, la política agraria ha de buscar una nueva legitimidad para que los agricultores puedan seguir recibiendo recursos públicos; la generación, 0 no destrucción, de empleo, la equidad en la distribución de las ayudas, la calidad de los al imentos y su contribución a la ordenación del territorio y la protección del medio ambiente, son algunos elementos que emergen en los debates sobre el futuro de las políticas agrarias y de desarrollo rural.

En sexto lugar, que la capacidad de los distintos grupos sociales para acceder a los recursos ofrecidos por el nuevo marco de oportunidades es diferente de unos a otros, dependiendo de su posición socioeconómica y del lugar ocupado en la estructura social. D e ahí que el contenido y orientación de las políticas públicas destinadas a regular la sociedad rural tenga una importancia fundamental, al reforzar las desigualdades ya existentes o facilitar el acceso a los recursos de los grupos en situaciones más desfavorecidas. El cierre social que experimentan las mujeres residentes en el medio rural, la desigual posición del pequeño campesinado y de la población asalariada agrícola respecto al mercado laboral, Ios problemas de la población que reside en zonas de montaña o en hábitats dispersos para acceder a servicios y equipamientos, o los problemas de endeudamiento de las explotaciones familiares modernizadas, son situaciones que muestran cómo el aprovechamiento de las oportunidades que ofrece el actual contexto de cambios depende, en gran medida, de factores estructurales que pueden ser removidos por la intervención de los poderes públicos mediante políticas regidas con criterios de equidad.

En definitiva, en un contexto marcado por la diversidad de las demandas y la pluralidad de los intereses que confluyen en el mundo rural, las políticas también se diversifican, reformulándose las viejas políticas agrarias orientadas hacia la regulación de los mercados y la mejora de las estructuras y emergiendo nuevas políticas orientadas a regular las múltiples funciones de los espacios rurales. $\mathrm{N}$ uevas y viejas políticas, nuevos y viejos actores, conviven en este periodo de transición, dándole a la sociedad rural un dinamismo de dimensiones desconocidas, un dinamismo que ofrece una nueva estructura de oportunidades a sus distintos grupos sociales. Esta estructura es sólo un escenario para la acción individual y colectiva de la población que reside en las zonas rurales, siendo los propios sujetos los que, a través de sus particulares modos de interpretarla, definen sus preferencias y, de acuerdo con sus capacidades, aprovechan los recursos que tienen a su disposición. 


\section{Bibliografía}

BAGER, T. (1996). O rganizations in sectors. Explaining the dissemination of formal organization in economic sectors. Esbjerg: SU C Press, D K.

BOUd ON, R. (1981). La lógica de lo social. M adrid: Rialp.

CAsquete, J. (1998). Política, cultura y movimientos sociales. Bilbao: Bakeaz.

ClimENT, V. (1998). «La percepción ambiental en el ámbito productivo». Revista Internacional de Sociología, núm. 19-20, enero-agosto, p. 279-293. CSIC.

DAUGBJERG, C. (1997a). «Policy networks, rational choice institutionalism and sociological institutionalism». ALF Working Paper. Esbjerg (DK): South Jutland University C entre.

- (1997b). «R eforming the CAP: The roles of Policy N etworks and Broader Institutional Structures». ALF Working Paper. Esbjerg (DK): South Jutland U niversity $C$ entre.

Delorme, H .; Le Theule, F.G. (1996). «Réforme dela PAC et U ruguay Round: vers une Europe libérale». En Jo LLIVET, M.; EIZNER, N. (ed.). L'Europe et ses campagnes, p. 275-294. París: Presses de Sciences Politiques.

D ONATI, P. (1997). «El desafío del universalismo en una sociedad multicultural», Revista Internacional de Sociología, núm. 17, mayo-agosto, p. 7-39. CSIC.

Entrena, F. (1998). Cambios en la construcción social de lo rural. D e la autarquía a la globalización. M adrid: Tecnos.

ENTREN A, F.; M OYAN O, E. (1997). «C ooperativismo y representación de intereses en la agricultura española». En Gómez Benito, C.; GonzÁlez Rodríguez, J.J. (ed.). Agricultura y Sociedad en la España contemporánea, p. 797-816. M adrid: Centro de Investigaciones Sociológicas y M APA.

Frouws, J.; VAN TATEN H OVE, J. (1993). «Agriculture, environment and the State: the development of agri-environmental policy-making in the $\mathrm{N}$ etherlands». Sociologia Ruralis, XXXII (2), p. 220-239.

García SAnZ, B. (1996). La sociedad rural española ante el siglo Xxı. M adrid: Serie Estudios del MAPA.

GARRID O, F. (1999). Análisi de las actitudes, discursos y estrategi as de los agricultores y sus organizaciones profesionales ante la introducción de métodos de desarrollo sostenible en la agricultura europea. Tesis doctoral. U niversidad de Córdoba).

GARRID O, F.; M OYAN O, E. (1998). «Actores sociales y políticas agroambientales en la U nión Europea». Política y Sociedad (ha sido aceptado para su publicación en el último número de 1998).

Gómez Benito, C.; GonzÁlez Rodríguez, J.J. (1999). I dentidad y profesión en la agricultura familiar. Serie 0 piniones y Actitudes, núm. 24. M adrid: CIS.

GRUPO DE BRUgGe/BRujas (1997). Por un cambio necesario en la agricultura europea. $M$ adrid: Servicio de Publicaciones del M APA.

H ERvieu, B. (1997). Los campos del futuro. M adrid: Serie Estudios del M APA (edición original en francés en 1994, en la editorial Boulin).

In glehart, R. (1977). The Silent Revolution: Changing Values and Political Styles among Western Publics. Princenton, N .J.: Princenton U niversity Press (hay versión en español en el CIS, con el título EI cambio cultural en las sociedadesindus triales avanzadas, 1991). 
Jiménez Guerrero, M.M. (1998). Aspectos socioeconómicos del desarrollo local en

España. Tesis doctoral. U niversidad de Córdoba.

M ORALES, R. (1997). «D esarrollo y transformaciones históricas del Sindicato de O breros del Campo (SO C) (1976-1994)». Sociología del Trabajo, núm. 32, invierno, p. 31-50.

M OYAN O, E. (1997). «Acción colectiva y organizaciones profesionales agrarias en España». En Góm ez Ben ITo, C.; G on ZÁlez Rodríguez, J.J. (ed.). Agricultura y Sociedad en la España contemporánea. M adrid: Centro de Investigaciones Sociológicas y M APA, p. 773-796.

M OYAN O, E.; PAN IAGUA, A. (1998). «Agricultura, espacios rurales y medio ambiente». Revista Internacional de Sociología, núm. 19-20, enero-agosto, p. 127-152. CSIC.

N avarro Yáñez, C. (1997). Innovación democrática en el Sur de Europa. Tesis doctoral. Universidad Complutense de M adrid.

O LIVEIRA BAPTISTA, F. (1998). «Agricultura y desarrollo rural en la Europa del Sur». Anuario de la U PA. M adrid: Fundación de Estudios Rurales.

REN ARD, M .C. (1996). Les interstices de la globalization. Tesis doctoral. Universidad de Toulouse Le M irail.

- (1998). «M undialización, sustentabilidad y consumo de alimentos: el caso de la red de café equitativo». Revista Internacional de Sociología, núm. 19-20, p. 225-245. CSIC.

SM ITH, M J. (1990). The policies of agricultural support in Britain. The development of the Agricultural Policy Community. D artmouth: Aldershot.

Th O M PSO N, P.B. (1995). The Spirit of the Soil. Agriculture and Environmental Ethics. Londres: Routledge.

W HITBY, M . (ed.) (1996). The European Environment and CAP Reform: Policies and Prospects for Conservation. CAB International. U .K. 